\title{
Conservation tillage achieves record acreage, yields
}

$\mathrm{B}$ etween 2008 and 2010, Central Valley farmers switched to conservation tillage on more than 344,000 acres used to grow row crops such as corn and wheat silage; meanwhile, in their 11th year of field research, UC scientists studying no-tillage practices achieved record yields in cotton and tomato.

A survey conducted in 2010 found that the amount of farmland under conservation tillage statewide grew by nearly $20 \%$ to nearly 1 million acres compared to a similar survey conducted in 2008, and by nearly $50 \%$ since surveying began in 2004.

Conservation tillage, a suite of low-impact cultivation practices that include leaving crop residues such as corn stalks in fields and planting new crops on top, significantly decreases the number of tractor passes needed to

Tulare and Yolo). Crops surveyed included silage, grains, tomatoes, cotton, dry beans and melons.

Farmers using conservation tillage also reported reductions in operating costs from $30 \%$ to $40 \%$ each year. Since 2004, farmers have saved more than $\$ 75$ million, the survey found, and nearly half of all row-crop acreage in the San Joaquin Valley is now farmed using conservation tillage.

\section{Record no-tillage yields achieved in 2011}

UC scientists for the first time achieved the same yields in cotton and tomato research plots managed under conservation tillage as they did on adjacent plots using conventional tillage practices.

"After toiling for more than a decade, we've finally succeeded in putting the pieces together this past season," said Mitchell, UC Cooperative Extension specialist in the Department of Plant Sciences at UC Davis. A cropping systems expert, Mitchell is based at the Kearney Agricultural Research and Extension Center in Parlier.

Researchers harvested 3.4 bales per acre of cotton and 53 tons per acre of processing tomatoes using no-tillage techniques. Plots managed with conventional tillage practices averaged about 3.4 bales per acre for cotton and 49 tons per acre for tomatoes.

The research was conducted at the UC West Side Research and Extension Center near Five Points. Mitchell and his Five Points team are part of CASI, a diverse group of more than

Planting with conventional tillage, left, generates dust; with conservation tillage, right, residues left on the surface prevent soil erosion and protect air quality.

prepare fields for planting. This results in dramatically lower fuel, labor and maintenance costs for farmers and less dust and diesel pollution in the air.

"No-till makes sense as a means for lowering production costs, and cutting dust and potentially greenhouse gas emissions," said Jeffrey P. Mitchell, head of the UC Conservation Agriculture Systems Initiative (CASI), which conducted the survey with the nonprofit organization Sustainable Conservation.

"No-till also improves soil functions, such as increased carbon storage, greater stability of soil aggregates, increased porosity and water infiltration, and a larger population of earthworms" (see page 55).

The survey is part of

For more information:

Conservation Agriculture Systems Initiative http://ucanr.org/CASI

Sustainable Conservation http:/ www.suscon.org an ongoing comparison of annual row-crop acreage farmed under a variety of tillage methods in nine Central Valley counties (Fresno, Kern, Kings, Madera, Merced, Sacramento, San Joaquin, 1,800 farmers, industry representatives, UC and other academic faculty, and Natural Resource Conservation Service and other public agency members.

Scientists established the cotton crop by direct seeding into beds that had not been touched since the preceding tomato crop, except by two herbicide sprays. The 2011 tomato crop was established with a no-tillage transplanter following the 2010 cotton crop, which had only been shredded and root-pulled under a waiver granted by the California Department of Food and Agriculture's Pink Bollworm Eradication Program.

The benefits of no-tillage farming have been recognized by researchers and farmers in other regions, such as the U.S. Great Plains and the Pacific Northwest, much of Canada and large areas of South America.

$\mathrm{UC}$ researchers estimated that switching to no-tillage reduced expenditures by about $\$ 135$ per acre for the tomato crop and about $\$ 40$ per acre for cotton. "These benefits start to pile up pretty fast once longer-term and broader sustainability goals are factored in," Mitchell said. 